\title{
Optical characterisation and photothermal conversion efficiency of a water-based carbon nanofluid for direct solar absorption applications
}

\author{
Alexandra Gimeno-Furio ${ }^{1}$, Raúl Martínez-Cuenca ${ }^{1}$, Rosa Mondragón ${ }^{1}$, Antonio Fabian Vela \\ Gasulla $^{1}$, Carlos Doñate-Buendia ${ }^{2}$, Gladys Minguez-Vega ${ }^{2}$, Leonor Hernandez*1 \\ ${ }^{1}$ Department of Mechanical Engineering and Construction, Universitat Jaume I, Avda. Sos \\ Baynat sn, Castellón, 12071, Spain \\ ${ }^{2}$ GROC-UJI, Institute of New Imaging Technologies, Universitat Jaume I, Avda. Sos Baynat sn, \\ Castellón, 12071, Spain
}

*Corresponding author: Ihernand@uji.es

\begin{abstract}
Carbon nanoparticles are very useful in solar thermal applications as they absorb much of the solar spectrum and can be inexpensive. Water-based carbon nanofluids with two different concentrations ( 3 and $33 \mathrm{mg} \cdot l^{-1}$ ) were prepared with sodium dodecyl sulphate as surfactant to achieve good high-temperature stability with a constant mean particle size of $200 \mathrm{~nm}$ at $25^{\circ} \mathrm{C}$ and $85{ }^{\circ} \mathrm{C}$. The morphology of the nanoparticles was observed by Transmission Electron Microscopy and the particle size distribution was studied using Dynamic Light Scattering at room and high temperature. Ballistic transmittance, absorption coefficient and scattering albedo of the three fluids were measured by a spectrophotometer with and without an integrating sphere using the Kubelka-Munk theory. The average value of the absorption coefficient showed important increases when comparing water against the nanofluid with the highest concentration (from 0.1 to $3.3 \mathrm{~cm}^{-1}$ ). Finally, the temperature change achieved when lighting the samples with an artificial sunlight simulator were measured and photothermal conversion efficiencies were evaluated, with increases of up to $200 \%$ when comparing nanofluid and base fluid. The results of this study show this kind of nanofluids to be very interesting for increasing the overall efficiency of the direct absorber solar collectors.
\end{abstract}

\section{Keywords}

Solar nanofluids; carbon black nanoparticles; high temperature stability; optical properties; photothermal efficiency

\section{Symbols}

$C_{p}$

loss coefficient

$\mathrm{kJ} \cdot \mathrm{s}^{-1} \cdot{ }^{\circ} \mathrm{C}^{-1}$

specific heat

$\mathrm{kJ} \cdot \mathrm{kg}^{-1} \cdot{ }^{\circ} \mathrm{C}^{-1}$

E

extinction coefficient

$\mathrm{cm}^{-1}$

F

sunlight absorbed fraction

$(-)$

$I_{0}$

total incident light

$\mathrm{W} \cdot \mathrm{m}^{-2} \cdot \mathrm{nm} \mathrm{m}^{-1}$ 


\begin{tabular}{|c|c|c|}
\hline$I_{T}$ & transmitted light & $\mathrm{W} \cdot \mathrm{m}^{-2} \cdot \mathrm{nm}^{-1}$ \\
\hline$I_{B S}$ & backward scattered & $\mathrm{W} \cdot \mathrm{m}^{-2} \cdot \mathrm{nm}^{-1}$ \\
\hline$I_{T+F S}$ & forward scattered and transmitted light & $\mathrm{W} \cdot \mathrm{m}^{-2} \cdot \mathrm{nm}^{-1}$ \\
\hline$I_{R+B S}$ & backward scattered and transmitted light & $\mathrm{W} \cdot \mathrm{m}^{-2} \cdot \mathrm{nm} \mathrm{m}^{-1}$ \\
\hline$I_{s}$ & solar irradiance & $W \cdot m^{-2} \cdot n m^{-1}$ \\
\hline K & absorption coefficient & $\mathrm{cm}^{-1}$ \\
\hline$\lambda$ & wavelength & $\mathrm{nm}$ \\
\hline$m$ & mass & $\mathrm{Kg}$ \\
\hline$n$ & refractive index & $(-)$ \\
\hline$\eta$ & efficiency & $(\%)$ \\
\hline$R$ & reflectance & $(-)$ \\
\hline$S$ & scattering coefficient & $\mathrm{cm}^{-1}$ \\
\hline Sabs & spatial distribution of the absorbed energy & $(-)$ \\
\hline$\omega$ & scattering albedo & $(-)$ \\
\hline$t$ & time & s \\
\hline$T$ & temperature & ${ }^{\circ} \mathrm{C}$ \\
\hline$T_{a}$ & ambient temperature & ${ }^{\circ} \mathrm{C}$ \\
\hline$T_{b}$ & ballistic transmittance & $(-)$ \\
\hline$T_{0}$ & initial temperature & ${ }^{\circ} \mathrm{C}$ \\
\hline$W_{a b s}$ & absorbed power & w \\
\hline$W_{\text {loss }}$ & loss power & W \\
\hline$W_{\text {measured }}$ & measured power & w \\
\hline$W_{\text {sample }}$ & sample power & w \\
\hline$x$ & sample thickness & \\
\hline
\end{tabular}

\section{Abbreviations}

$\mathrm{CB}$

DASC

DLS

HTF

NF
Carbon Black

Direct Absorption Solar Collector

Dynamic Light Scattering

Heat Transfer Fluid

Nanofluid 
NP

SDS

SWCNH

TEM
Nanoparticles

Sodium Dodecyl Sulphate

Single-wall carbon nanohorn

Transmission Electron Microscopy 


\section{Introduction}

Nowadays, the consumption of energy worldwide continues to increase, which causes increments in the energy market, decreases in availability and energy security, and growing environmental concern, which is rapidly changing the global energy scenario. Energy and water are basic and indispensable resources for our current lifestyle, as well as for sustainable economic development. Modern societies depend mainly on fossil fuels [1] and, for this reason, securing and developing renewable sources of energy are some of the greatest challenges that humanity is facing today.

The use of renewable energy sources is an optimal solution to overcome these challenges. Solar energy has the greatest potential of the available renewable energies as, properly managed, it could provide enough energy to exceed the total estimated lifetime of fossil fuel resources in a single year [1,2]. The direct absorption solar collector (DASC) concept is an interesting alternative to improve the efficiency of collecting solar energy and converting it into useful energy [3]. This new idea for a solar thermal collector was described by [4] and it introduces a concept in which solar radiation is volumetrically absorbed and transported by the working fluid itself. The majority of the heat transfer fluids (HTF) used (water, glycol, oils, etc.) are transparent for most of the solar spectrum $[5,6]$, which means that the addition of some additives to the working fluid can enhance solar their radiation absorption properties.

In recent years, it has been demonstrated how the properties of stable and homogeneous suspensions of nanoparticles (NP) in the base fluids, the so-called nanofluid (NF), present several thermal and optical advantages with respect to the standard employed HTFs employed for solar energy power production [7-14]. The number of studies of nanofluids for DASC has increased rapidly over these last years $[15,16]$, as very low concentrations (and therefore more easily stabilising suspensions) imply important improvements in the harvesting of solar energy. Among the nanoparticles tested for these solar thermal absorption systems, carbon nanomaterials are the most promising due to their outstanding optical and thermal properties. Different carbon configurations from carbon black [13] to graphite [16, 17], as well as carbon nanostructures (e.g. single-wall, multi-wall and functionalised nanotubes $[16,18,19,20]$, carbon nanohorns $[9,12,13,21]$, graphene and graphene oxide $[22,23])$ have been studied in these applications.

Nanofluids can be fabricated using different techniques. The two-step method is the most commonly used for carbon-based nanofluid preparation, and only a few studies have used the one-step method for synthesising carbon nanomaterials [24-26], mainly due to the high costs and specific and sophisticated equipment required. Maintaining a homogenous dispersion for long periods of time and at the working temperatures reached by the nanofluid is one of the major problems for DASC applications. As DASC is still mainly focused on low temperatures (below $100{ }^{\circ} \mathrm{C}$ ) and due to the hydrophobic nature of the carbon nanomaterials, different methods have been developed to achieve stable nanofluids $[27,28]$. Among them, non-covalent functionalisation with the addition of surfactants is a common solution that has been proved to yield good results without increasing the cost and time of the method of production of the nanofluids.

Nanoparticle material and morphology are fundamental parameters of the optical properties of nanofluid, which in return determine the amount of solar radiation energy absorbed. The Rayleigh, Mie, Maxwell-Gartnett and Kubelka-Munk approaches are some of the popular theories for modelling optical properties $[29,30]$. The key element to simulate the behaviour of 
the nanofluid is to know the absorption coefficient. The extinction coefficient that accounts for the absorption and scattering coefficient can be measured experimentally with a spectrophotometer. In the pioneering articles on the study of solar nanofluids, the effect of the scattering was neglected. Then, the effect of the scattering was considered theoretically using mainly the Mie or Rayleigh theories. However, these theories suffer from some deficiencies such as the fact that mainly spherical nanoparticles are considered and the effects of polydispersity and aggregation of the nanoparticles are neglected. For this reason, in this paper we introduce the Kubelka-Munk theory, which provides a more realistic description of the real behaviour of the solar nanofluid due to the fact that is a semiempirical model.

To cross the border from basic research to an industrial application the economic benefits and the environmental impact should be considered. From an environmental point of view, it has been demonstrated that over the expected lifetime of the solar collectors there will be a reduction of $740 \mathrm{~kg}$ of $\mathrm{CO}_{2}$ in a nanofluid-based collector in comparison to a conventional one [31]. From the point of view of the economic benefits, global solar energy production is predicted to be the fastest developing type of energy generation between 2012 and 2040. Moreover, the total worldwide installed capacity of concentrating solar thermal technologies in 2016 is expected to double by 2022 reaching $10 \mathrm{GW}$ [32]. So any small improvement in the capability of the solar nanofluid to improve the efficiency of a solar collector will lead to big economic benefits in the coming years.

Different experimental facilities have been employed in the literature to evaluate carbon-based nanofluids for direct solar absorption [33-40]. Among carbon-based nanofluids, those using carbon black (CB) nanoparticles possess similar optical properties of other carbon-based materials are easily available, less expensive and easily available, therefore promising DASC applications. Most of the previous works [41-44] on the water-based CB nanofluids address the issues of optical properties, temperature rise, photothermal conversion efficiency and steam generation. Han et al. [41] investigated absorption property and transient temperature profile, obtaining enhancements in temperature up to $7.5^{\circ} \mathrm{C}$ for 7.7 vol\% aqueous $\mathrm{CB}$ nanofluid after 42 minute of sunlight illumination. In a similar study, Wang et al. [42] observed for $0.05 \mathrm{wt} \% \mathrm{CB}$ water nanofluid a temperature increase over the base fluid of $13^{\circ} \mathrm{C}$ after 2 hours of exposure to sunlight. Zeiny et al. [43] experimentally investigated optical and photo-thermal properties observing increases of $125 \%$ was achieved in photothermal conversion efficiency by $100 \mathrm{mg} / \mathrm{l}$ CB-water nanofluid. Ulset et al. [44] reached $73 \%$ efficiency in steam generation in parabolic concentrator at 0.76 sun using a 3 wt\% water-based $C B$ nanofluid as the working fluid.

In this work, the base fluid used was water, and the $\mathrm{CB}$ based nanofluids were produced by the two-step method. To offset the hydrophobic behaviour of the carbon NP, sodium dodecyl sulphate (SDS) was employed as a surfactant agent to ensure that nanoparticles remain well dispersed in the water. Two different water-based carbon nanofluid samples with different concentrations have been evaluated. The main characterisation was focused on the morphology, stability and optical properties as well as the conversion of radiation into thermal energy. Morphology was studied using Transmission Electron Microscopy (TEM). Stability and particle size distribution were measured using the Dynamic Light Scattering (DLS) technique. Different optical properties such as absorption, scattering coefficients and solar absorbed energy of the different samples have been measured or calculated. These parameters were obtained by combining experimental techniques including spectrophotometers and integrating sphere, and also the Kubelka-Munk theory. To complete the characterisation of the nanofluids synthesised for DASC, the photothermal conversion efficiency was evaluated with a new 
formulation for an experimental facility including an artificial sunlight simulator. In this paper we introduce, for the first time to our knowledge, a photothermal conversion efficiency evaluation fitting the transient temperature evolution of the fluids in an evaluation of the power absorbed by the fluid including the incident radiation and the heat losses due to convection and radiation. This method provides a global photothermal conversion efficiency for each tested fluid, avoiding the difficulties of comparing transient results and of uncertainties due to temperature signals in the equation used in previous works $[43,45,46]$.

\section{Materials and methods}

\subsection{Synthesis of the nanofluid}

To study the effect of the concentration on the performance of the NF, two water-based carbon nanofluids were synthesised with different nanoparticle loadings: $3 \mathrm{mg} \cdot \mathrm{l}^{-1}$ (NF1) and $33 \mathrm{mg} \cdot \mathrm{l}^{-1}$ (NF2). The base fluid used herein was Milli-Q water (ultrapure, 18.2 M 2 ). Carbon black nanoparticles (ELFTEX 570, Cabot Corporation) were selected for their solar absorption ability. According to the manufacturer, they consist of spherical amorphous carbon particles with a primary diameter of $10 \mathrm{~nm}$. A non-covalent functionalisation of the nanoparticle was chosen as stabilisation. This method allows a balance between effectiveness and simplicity to be reached without any considerable increase in the cost of the nanofluids. The surfactant used in this case was sodium dodecyl sulphate (SDS, Sigma Aldrich, Ltd.), which was selected for its chemical affinity and its effective thermal behaviour at high temperatures.

The procedure for synthesising water-based carbon nanofluids was carried out in two steps: the surfactant was first dissolved in the base fluid by magnetic stirring for 1 minute. Then the carbon black nanoparticles were added and dispersed using an ultrasound probe (Sonopuls, HD2200, Bandelin) for 1 minute. The surfactant-to-nanoparticle weight ratio was 1:1, based on previous articles $[7,47,48]$.

Figure 1 shows a picture of as-prepared nanofluids of different concentrations and water as the base fluid. 


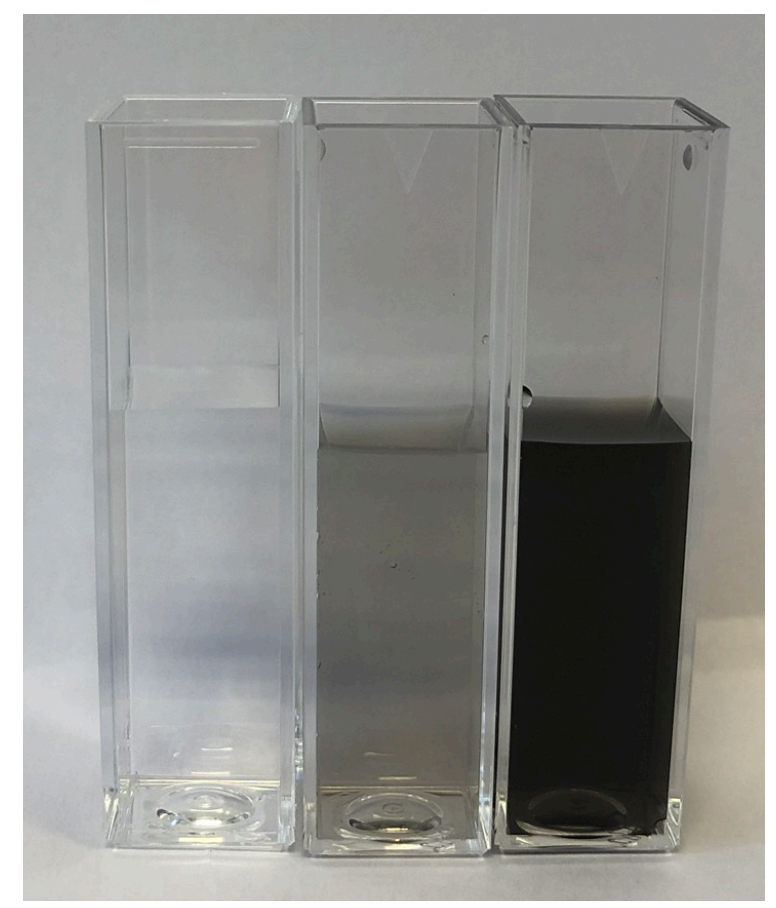

Figure 1 Samples of the base fluid and water-based carbon nanofluids with different concentrations.

\subsection{Experimental techniques}

In this section, the shape and size of the solar NFs were characterised using transmission electron microscopy, TEM and dynamic light scattering (DLS) techniques, respectively. The optical properties were determined with a Cary 500 spectrophotometer and an integrating sphere with a polytetrafluoroethylene coating, which guarantees a reflectance of $99 \%$ in the measured range. The experimental error in the measures carried out by the spectrophotometer is below $2 \%$. Finally, to measure the photothermal energy conversion efficiency of the samples, a specific setup was built.

\subsubsection{TEM}

The carbon nanoparticles were observed using a transmission electron microscope (JEM-1010, JEOL) operating at an accelerating voltage of $100 \mathrm{KV}$ with a resolution of $0.45 \mathrm{~nm}$ and an AMT RX80 (8 Mpx) a digital camera. A droplet of the NF was dispersed onto a carbon-coated copperbased TEM grid. The liquid content was then removed with the help of absorbent paper so that the solid particles would remain on the grid surface. The morphology and the primary particle size were then studied from the acquired images.

\subsubsection{DLS}

The size distribution of the NPs in the nanofluid was analysed using the DLS technique. This measures the light scattered by the particles due to their Brownian motion and the intensity of the signal is unequivocally related to their size.

The water-based carbon nanofluids were measured with a Malvern ZetaSizer Nano. This device is commonly used to measure particle size distributions in NFs by means of DLS. The equipment 
is composed of a laser, which illuminates the cell containing the sample, and a detector that acquires the intensity of the light scattered by the suspended particles. Both, the laser and the detector are enclosed in the device, and the hydrodynamic diameter is calculated based on the intensity of the scattered light at $173^{\circ}$. ZetaSizer has a built-in heating system that allows the samples to be heated up to $90^{\circ} \mathrm{C}$. The heating system consists of a Peltier that heats and cools samples in relation to the temperature sensor and the temperature coefficients generated in the internal system of the equipment [49].

\subsubsection{CARY 500 spectrophotometer}

The spectrophotometer employed was a CARY 500 (Varian) device composed of: a light source, which consists of a Xenon lamp, a photodetector located in front of the light emitter, and a cuvette holder to place the sample to be analysed. The operating principle of this system is to measure the intensity of the light being transmitted (ballistic transmittance, $T_{b}$ ) by the fluid by evaluating the intensity of the sample beam $\left(I_{0}\right)$ and the light received after passing through the sample $\left(I_{T}\right)$, as defined in Equation 1:

$$
T_{\mathrm{b}}=\frac{I_{\mathrm{T}}}{I_{0}},
$$

The measured ballistic transmittance in this case includes absorption, but also the scattering of the sample.

To measure the absorption of a sample, an integrating sphere is attached to the spectrophotometer. Figure 2 illustrates the detection geometry of the integrating sphere. Two laser beams are directed inside it, one towards the sample and the second serves as a reference. Once both beams enter the sphere, they impact the Teflon surface inside it and undergo many reflections, thus ensuring a homogeneous distribution of the radiation on the inner surface of the sphere before being captured by the photodetector (D) at the top of the sphere. Note that the reference beam enters the sphere through a diffusing window (R1) to reduce any losses that could arise from direct reflections at (R2). This beam monitors the changes in laser power during the measurement time required for a full wavelength scan. The sample beam enters the integrating sphere through a hole in port S1 and impinges directly upon port S2 (which can be tilted, as seen in Figure 2, or not). In practice, the sample can be placed in either port S1 or S2, depending on the desired property to be measured. To obtain the absorption spectrum, two different measurements are needed locating the NF in S2, tilted or not.

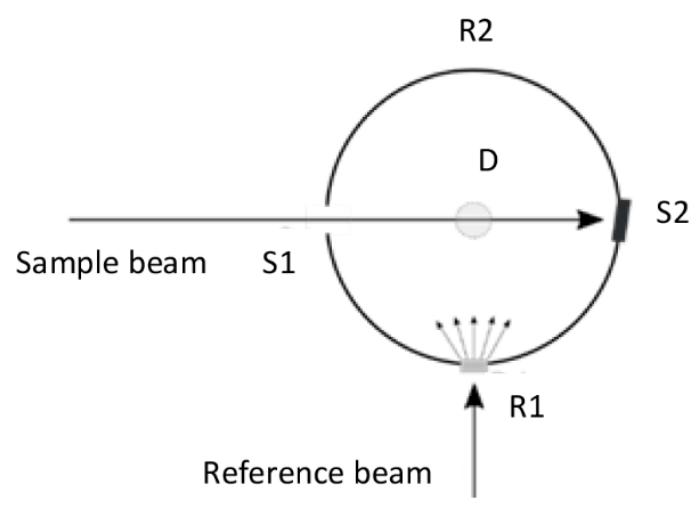


Figure $2 \mathrm{~A}$ schematic of the integrating sphere, including reference and sample beam paths and measuring port locations (S1 and S2).

For both measurements, port S1 was left open while a cuvette with the nanofluid was located in port $\mathrm{S} 2$ by removing the Teflon cap. The first measurement is performed by tilting the cuvette, and thus the resulting signal is proportional to the sum of the reflected and backward scattered light powers $\left(I_{R+B S}\right)$. The second measurement is acquired without tilting the cuvette, so that the resulting signal is proportional to the backward scattered light power $\left(I_{B S}\right)$. Finally, the reference intensity $\left(I^{\prime}\right)$ is measured leaving the S1 port empty and the S2 closed with the Teflon cap. After acquiring the above-mentioned measurements, the reflectance spectrum $(R)$ was obtained as in Equation 2:

$$
R=\frac{I_{R+B S}-I_{B S}}{I_{0}^{\prime}},
$$

The reflectance value together with the ballistic transmittance are employed for the complete calculation of the absorption $(K)$, scattering $(S)$ and extinction $(E=K+S)$, as in Equations 3 to 5, and the scattering albedo $(\omega=S / E)$ coefficients by the Kubelka-Munk theory using the following expressions [50]:

$$
\begin{gathered}
\frac{K}{S}=\frac{R^{2}-T_{b}{ }^{2}+1}{2 R}-1, \\
C=\sqrt{\frac{K}{S}\left(\frac{K}{S}+2\right),} \\
S=\frac{1}{C x} \operatorname{coth}^{-1}\left(\frac{T_{b}{ }^{2}-R^{2}+1}{2 R C}\right),
\end{gathered}
$$

where $x$ is the sample thickness, which in this case is $1 \mathrm{~cm}$ due to the path length of the quartz cuvette used in both experiments, with and without the integrating sphere.

The wavelengths range of the measurements employing the integrating sphere span the range from 400 to $1100 \mathrm{~nm}$. This range comprises $76.7 \%$ of the total solar radiation energy reaching the Earth and includes the highest solar radiation level. These measurements are performed at room temperature.

\subsection{Sunlight absorbed fraction}

The solar absorption ability of NFs is important in volumetric solar collectors and is evaluated by $F(x)$. This parameter calculates the sunlight-absorbed fraction of incident sunlight, $I_{S}(\lambda)$, which is absorbed in the fluid after propagation through a given distance inside the nanofluid, $x$. The $F(x)$ value is obtained by Equation 6 [12, 13]:

$$
F(x)=1-\frac{\int_{\lambda_{\min }}^{\lambda_{\max }} I_{S}(\lambda) \cdot e^{-K(\lambda) \cdot x} d \lambda}{\int_{\lambda_{\min }}^{\lambda_{\max }} I_{S}(\lambda) d \lambda},
$$


where $I_{S}(\lambda)$ is obtained from ASTM solar radiation [51], the spectral absorption coefficient $K$ is calculated by Equations 3 to 5 and the spectral range where the measurements are performed, $\lambda_{\min }=400 \mathrm{~nm}$ and $\lambda_{\max }=1100 \mathrm{~nm}$, define the integration bounds. The resulting value is, therefore, representative of the fraction of solar radiation absorbed by the sample within the specified wavelength range.

\subsection{Spatial distribution of absorbed energy}

The spatial distribution of absorbed energy $S_{a b s}(x)$ indicates the energy stored inside the nanofluid volume. This distribution, for a cold fluid in absence of convective mixing, is calculated by Equation $7[12,13]$ :

$$
S_{a b s}(x)=\frac{\int_{\lambda \min }^{\lambda \max } I_{S}(\lambda) \cdot K(\lambda) \cdot e^{-K(\lambda) \cdot x} d \lambda}{\int_{\lambda \min }^{\lambda \max } I_{S}(\lambda) d \lambda}
$$

where the values for $K, \lambda_{\min }, \lambda_{\max }$ and $I_{s}(\lambda)$ are the same as those used in Equation 6 . Distribution refers to a single-sided irradiated volume of fluid. This parameter is very useful for optimal system dimensioning, as it indicates the distance from the input surface at which energy absorption takes place. It is also an appropriate parameter to evaluate NFs as direct solar energy absorbers by optimising the type and concentration of the nanoparticles to be used in solar collectors.

\subsection{Photothermal conversion experimental setup}

The experiments were performed by means of collimated illumination from an artificial sunlight simulator (Oriel $626375 \mathrm{~W}$ Xe OZONE FREE). To achieve constant thermal and illumination conditions, the lamp was switched on 30 minutes before performing the experiment. The spectrum of the source is depicted in Figure 3, which shows that the sunlight simulator reproduces to a certain extent the spectral behaviour of the solar irradiance reaching the ground level, $I_{s}(\lambda)$. 


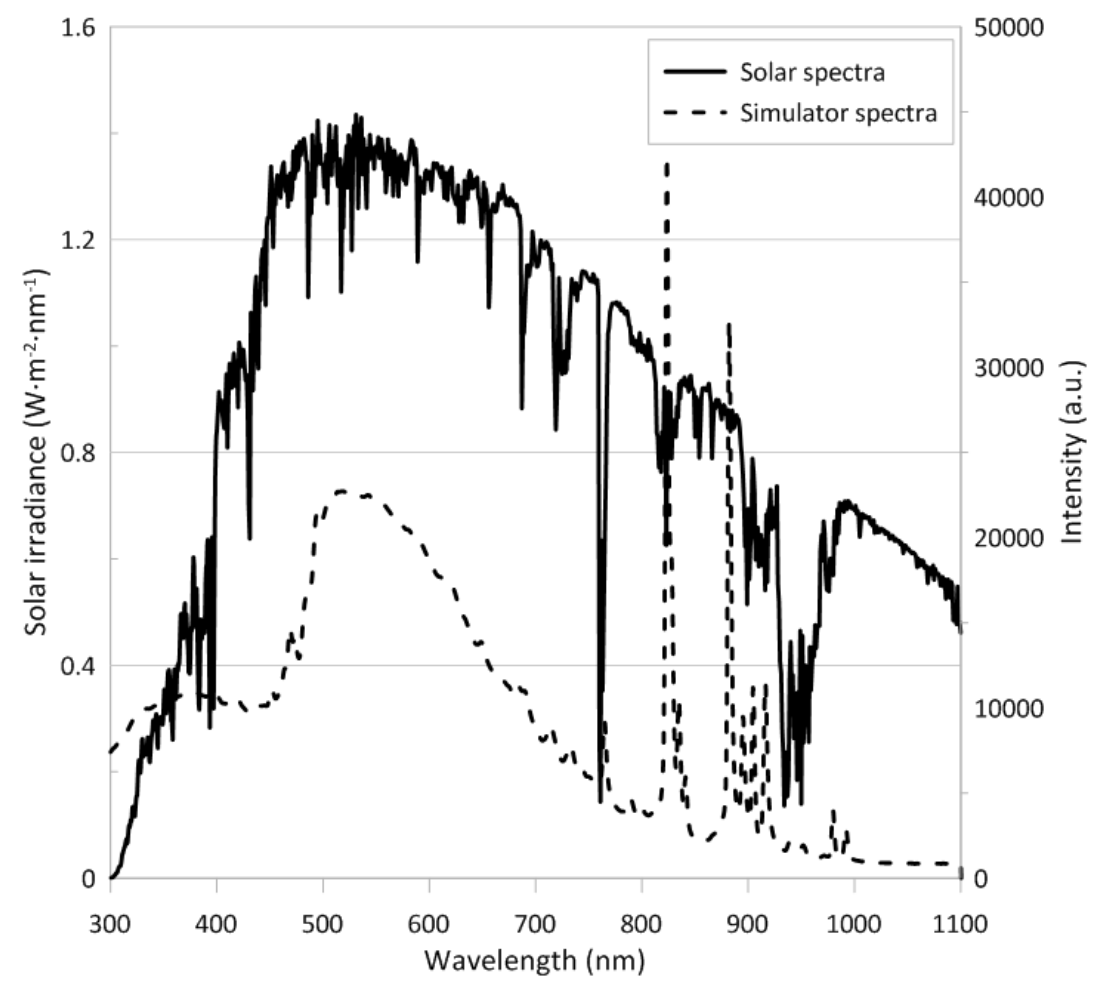

Figure 3 Solar (full line) and artificial sunlight simulator (dotted line) spectra.

The quartz glass tube in the experiment was custom-made for high temperature resistance. The tube contains a vacuum interlayer to reduce heat losses by convection to the ambient air. The fluids were placed in the inner-tube, which had a diameter of $25 \mathrm{~mm}$ and a length of $150 \mathrm{~mm}$. The diameter of the outer-tube was $50 \mathrm{~mm}$. The evolution of the temperature of the samples was registered with a data acquisition system composed of a data logger (Agilent 34970A) linked to a PC. As shown in Figure 4, a K-type thermocouple (RS PRO K-228-7451) with a measurement uncertainty of $\pm 1.5^{\circ} \mathrm{C}$ was placed inside the fluid. Its position remains constant with respect to the light source for all the experiments, i.e. in the centre of the cuvette and $2 \mathrm{~cm}$ below the surface of the liquid. Additionally, another thermocouple was employed to measure the ambient temperature. The experiments were performed in a closed isolated room to avoid the thermal effects of the environment and to work under more controlled conditions. Thanks to these controlled conditions, all the measurements performed in this work station showed a deviation lower than $1.5 \%$.

Figure 4 shows a picture of the experimental setup built for the temperature development of the NFs measurements. 


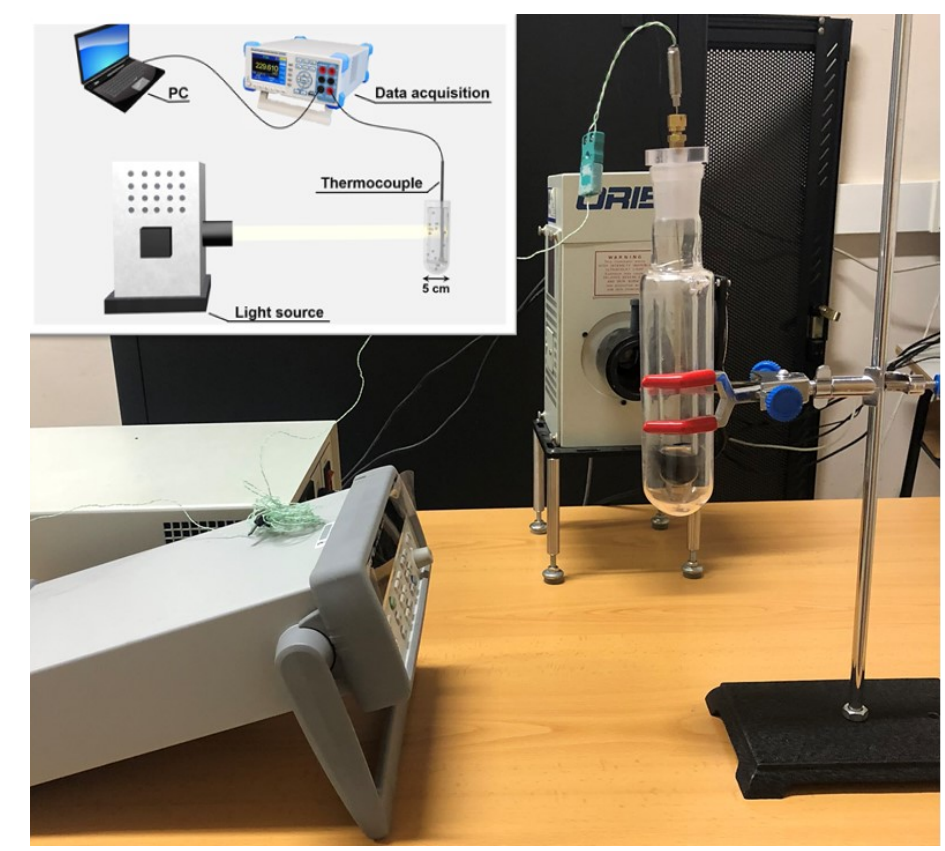

Figure $4 \mathrm{~A}$ picture of the photothermal experimental setup. A schematic view is shown in the inset.

The artificial sunlight simulator power at the location of the quartz glass tube ( $W_{\text {measured }}$ ) was measured by a potentiometer (Ophir 1Z01500, Nova Display). After that, the quart glass tube was located in the same position to ensure that the incident light power is known.

Considering the energy balance, the photothermal conversion efficiency $(\eta)$ is conventionally defined as the ratio between the energy power absorbed by the fluid $\left(W_{a b s}\right)$ and the incident radiation power that reaches to the fluid $\left(W_{\text {sample }}\right)$ in Equation 8:

$$
\eta(\%)=\frac{W_{a b s}}{W_{\text {sample }}} \cdot 100
$$

The efficiency was calculated based on the heating-up stage over the period between the beginning of the experiment and the time when the temperature of the fluid reaches its maximum.

$W_{\text {sample }}$ is calculated from $W_{\text {measured }}$ and a correction taking into account the losses caused by the light propagation through media with different refractive indexes. In order to calculate it, the following formula was applied [52]:

$$
W_{\text {sample }}=W_{\text {measured }} \cdot \frac{4 n_{2} n_{1}}{\left(n_{2}+n_{1}\right)^{2}} \cdot \frac{4 n_{1} n_{2}}{\left(n_{1}+n_{2}\right)^{2}} \cdot \frac{4 n_{2} n_{1}}{\left(n_{2}+n_{1}\right)^{2}} \cdot \frac{4 n_{2} n_{3}}{\left(n_{2}+n_{3}\right)^{2}}
$$

where $n_{1}, n_{2}$ and $n_{3}$ are the refractive indexes of the vacuum and air, quartz and fluid, respectively.

Furthermore, in order to obtain the power absorbed by the fluid $\left(W_{a b s}\right)$, a deeper balance is needed, including $W_{\text {sample }}$ and the heat losses due to convection and radiation $\left(W_{\text {loss }}\right)$, which can be defined as: 


$$
\begin{gathered}
W_{\text {sample }}=W_{a b s}-W_{\text {loss }} \\
m \cdot C_{p} \cdot \frac{d T}{d t}=W_{a b s}-\beta \cdot\left(T-T_{a}\right)
\end{gathered}
$$

where $m$ is the mass of the sample in the tube, $C_{p}$ is the specific heat capacity of the sample, $T$ is the temperature of the fluid, $B$ is the loss coefficient and $T a$ is the ambient temperature.

Finally, by integrating and defining the boundary initial conditions $\left(t=0 \rightarrow T=T_{0}\right)$, Equation 12 was obtained:

$$
T=\left[\frac{W_{a b s}}{\beta}+T_{a}\right]+\left[T_{0}-T_{a}-\frac{W_{a b s}}{\beta}\right] e^{-\frac{\beta t}{m C_{p}}}
$$

where $T_{0}$ is the initial temperature of the fluid. This equation can be fitted to an exponential curve to obtain the $W_{a b s}$, so that photothermal conversion efficiency (Equation 8 ) can be calculated.

\section{Results and discussion}

\subsection{Nanoparticle morphology and size}

Figure 5 shows a TEM image of the carbon nanoparticles. It can be observed that the primary diameters of the NPs are around $50 \mathrm{~nm}$ but they agglomerate to form clusters of a larger size (< $300 \mathrm{~nm})$.

The DLS measurements of the two NFs at different concentrations were carried out at $25^{\circ} \mathrm{C}$ and $85^{\circ} \mathrm{C}$. The results in Figure 6 show a mean diameter of around $200 \mathrm{~nm}$ in both cases, in good agreement with the cluster sizes observed by TEM. It can be concluded that the degree of dispersion of the nanoparticles in the base fluid is the maximum that can be achieved, and no formation of bigger agglomerates takes place in the nanofluid. These results, together with the low concentration of nanoparticles, are a good indicator of the suitability of the surfactant to achieve colloidal stability.

Moreover, to corroborate that the surfactant can withstand thermal cycling at high temperatures, DLS measurements were performed at $85^{\circ} \mathrm{C}$. In Figure 6 it can be observed that the mean particle size of the agglomerates is not affected by the temperature increase although a slight narrowing of the peak takes place. Two different effects appear when increasing temperature: on the one hand the decrease in the fluid viscosity leads to an increase in the Stokes sedimentation but on the other hand the Brownian motion responsible for the nanoparticle suspension is also increased. The combined effect may be the cause of the small differences observed, although they are negligible and stability is guaranteed. 


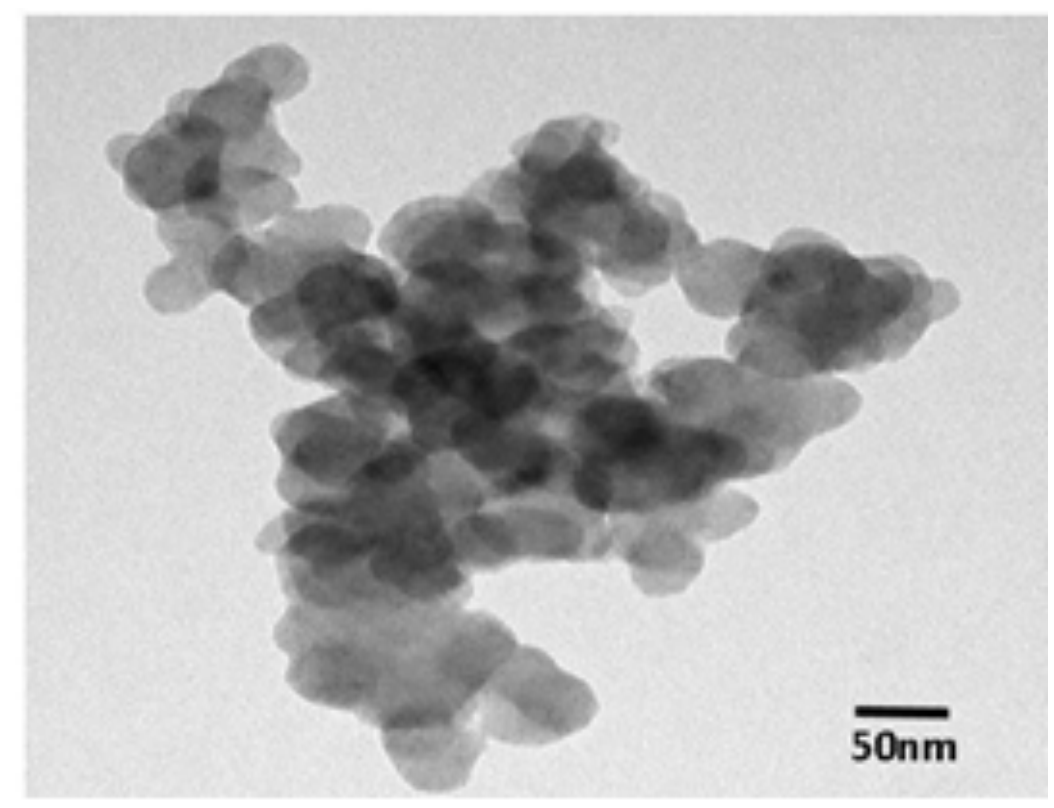

Figure 5 TEM image of carbon nanoparticles.
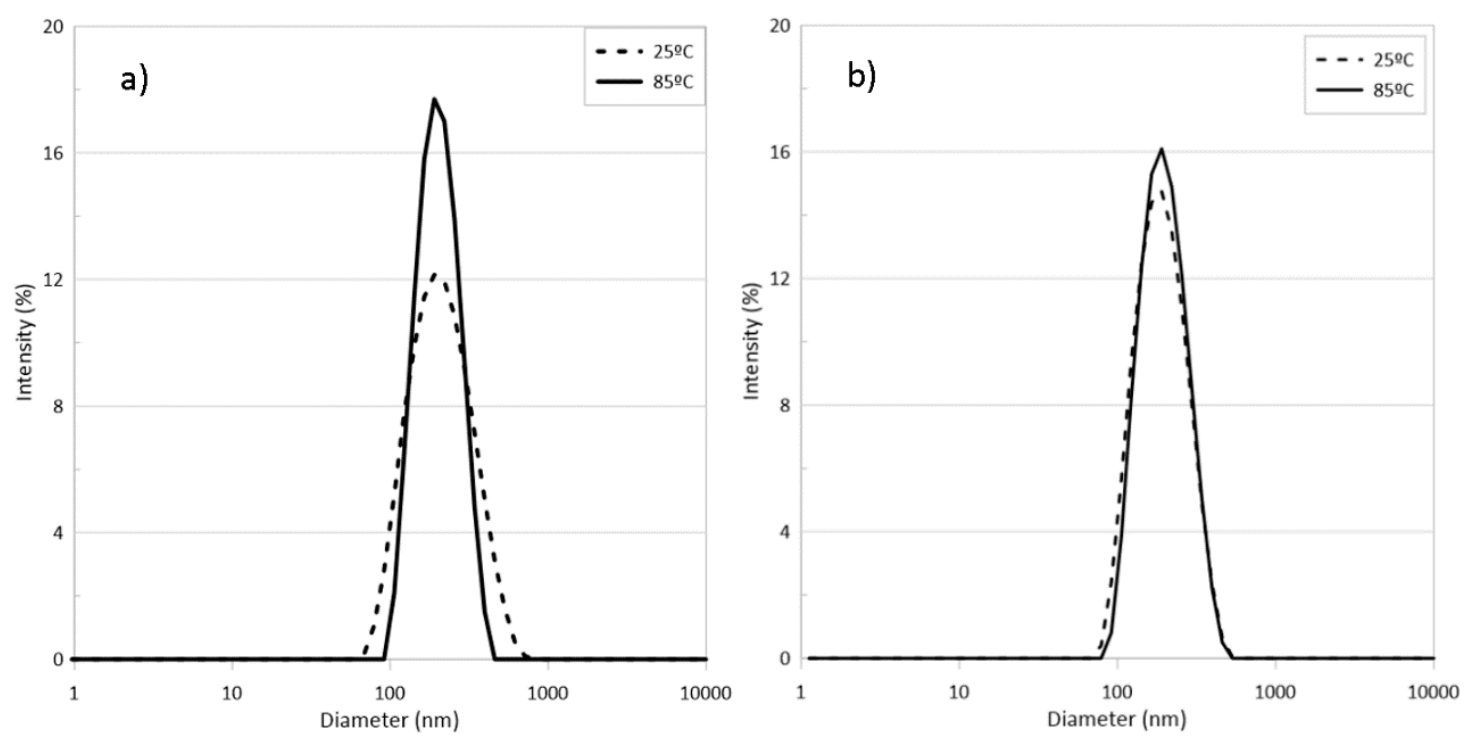

Figure 6 Particle size distribution of a) NF1 and b) NF2 at $25^{\circ} \mathrm{C}$ and $85^{\circ} \mathrm{C}$.

\subsection{Optical characterization}

Due to the importance of optical properties for solar NFs, different spectra were acquired in a spectrophotometer with and without the integrating sphere in order to achieve a deeper knowledge of the optical parameters that characterise the samples.

First of all, the ballistic transmittance spectra $(T b)$ for the base fluid and both NFs were measured with the spectrophotometer and are shown in Figure 7. Similar results were obtained for water and water + SDS in the concentration used for the NF synthesis, so only water values are included hereafter. The spectral transmittance values obtained for water are in accordance with the literature $[12,13,18]$ with a strong absorption band at $900-1000 \mathrm{~nm}$. Also, transmittance 
results for both nanofluids show similar trends to those found in previous research $[29,53]$, with significantly lower transmissions than their base fluid, indicating that the addition of carbon nanoparticles in water enhances solar absorption. This is due to the direct absorption of photons by carbon and on the other hand the scattering of light produced by the nanosized particles [12]. Compared to the base fluid, the transmittances of the nanofluids decreased with increasing NP concentration, which is associated to the enhancement of optical absorption and scattering [53].

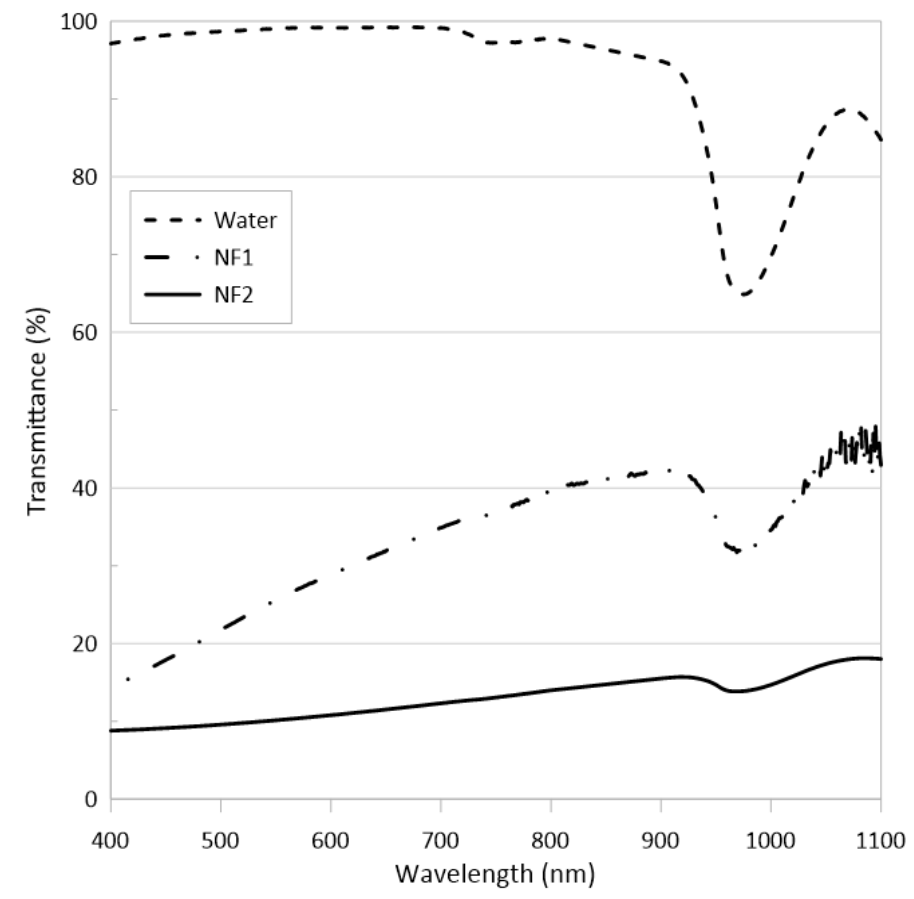

Figure 7 Ballistic transmittance of the base fluid (water) and the base fluid with carbon nanoparticles at two different concentrations (NF1 and NF2).

The water transmittance presents an averaged value within the measured wavelength range of $93 \%$ while for the nanofluids it decreases with increasing NP concentrations: $32 \%$ and $12 \%$ for NF1 and NF2, respectively. Even at the lowest carbon NP concentrations $\left(3 \mathrm{mg} \cdot{ }^{-1}\right)$, the average transmittance of the NF is about $66 \%$ lower than that in the base fluid.

To ensure the suitability of the applications of these NFs in solar energy technologies, the absorption coefficient $(K)$ was also evaluated. This coefficient was calculated using the different spectra acquired with and without the integrating sphere and using the Kubelka-Munk Theory.

Figure 8 illustrates that the synthesised water-based carbon NFs have significantly improved absorption coefficients compared to their base fluid, with higher absorption coefficients for shorter wavelengths. The average value of this coefficient over the measured range of wavelengths increases from 0.1 to $3.3 \mathrm{~cm}^{-1}$ when moving from the base fluid to the NF with the highest NP concentration. 


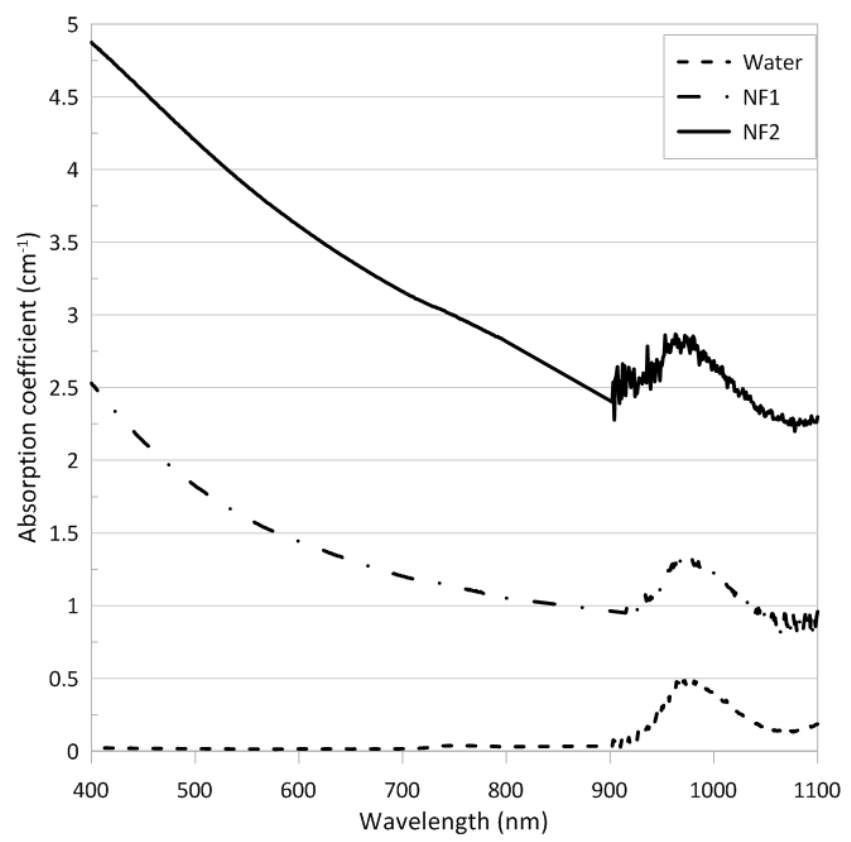

Figure 8 Absorption coefficient of the base fluid (water) and the base fluid with carbon nanoparticles at two different concentrations (NF1 and NF2).

The scattering albedo coefficient (Figure 9) of the NFs was also calculated to evaluate the amount of light that is scattered by the nanoparticles and, consequently, is not directly absorbed and does not contribute to the heating of the NF. The spectral scattering albedo are around 0.1, indicating that most of the extinct light in this NF was absorbed and less than $10 \%$ was scattered. These results are consistent with those previously shown in the literature $[13,29,54]$, with constant scattering albedo values as a function of the light wavelength of around $5 \%$ for SWCNH suspension in water and around $15 \%$ in the case of Indian ink (based on carbon-black) aqueous.

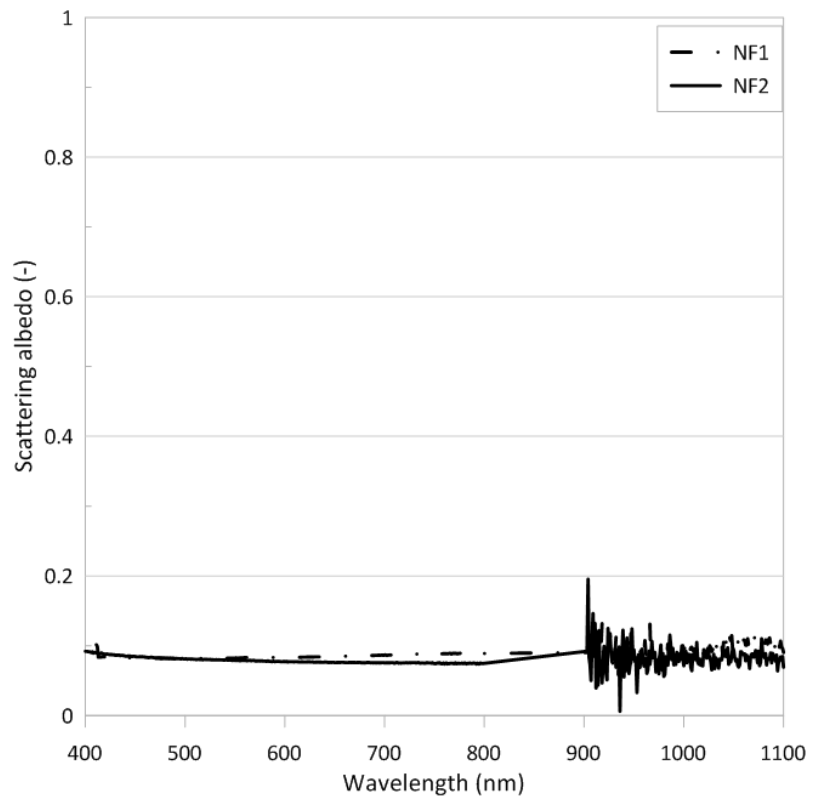


Figure 9 Scattering albedo of the water- based carbon nanofluids at two different concentrations (NF1 and NF2).

Figure 10 compares the fraction of sunlight absorbed by the investigated fluids $(F(x))$, as obtained from Equation 6 . The trends found clearly show that employing nanofluids for a solar collector allows the sunlight to be absorbed within a lower penetration distance, just in few centimetres. Their implementation in a solar collector would therefore improve its compactness, thus reducing the volume of liquid required and generally lowering the cost of the system.

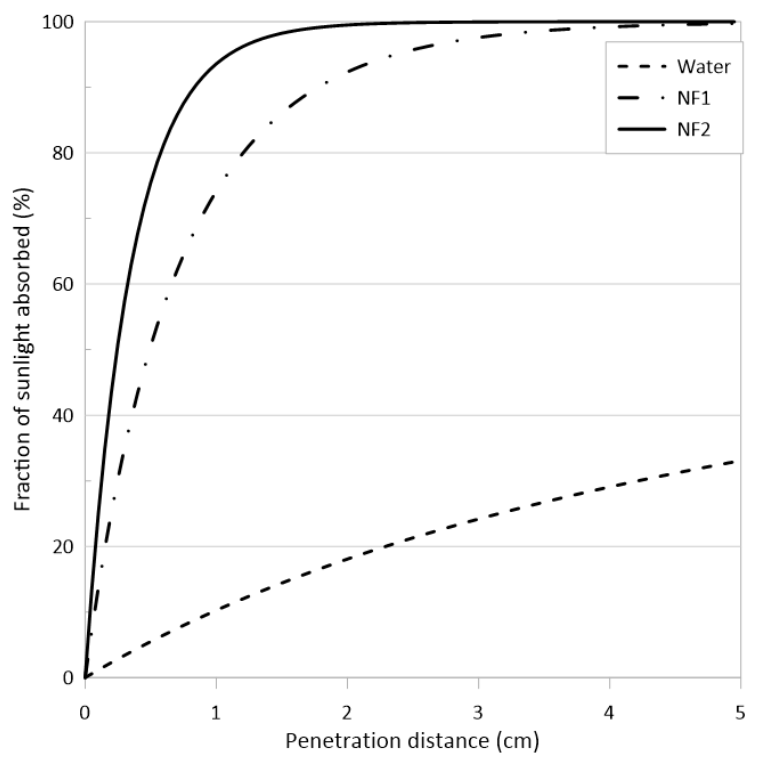

Figure 10 Fraction of sunlight absorbed with respect to the penetration distance of the base fluid (water) and the base fluid with carbon nanoparticles at two different concentrations (NF1 and NF2).

It has been noted that the addition of carbon NPs to the base fluid clearly influences the solar radiation absorption by reducing the distance needed to completely absorb the sunlight. To quantitatively assess the differences from Figure 10 it is deducted that while NF2 reached around $100 \%$ of absorption at a liquid thickness of $2 \mathrm{~cm}$ and around $5 \mathrm{~cm}$ in the case of NF1, the base fluid only achieved around $30 \%$ of absorption for this last penetration distance. This confirms the positive effect of the nanoparticle spectral characteristics for efficient solar energy storage.

The local stored energy distribution (Figure 11) is calculated for both NFs as a function of the distance from the sunlight input surface following Equation 7. 


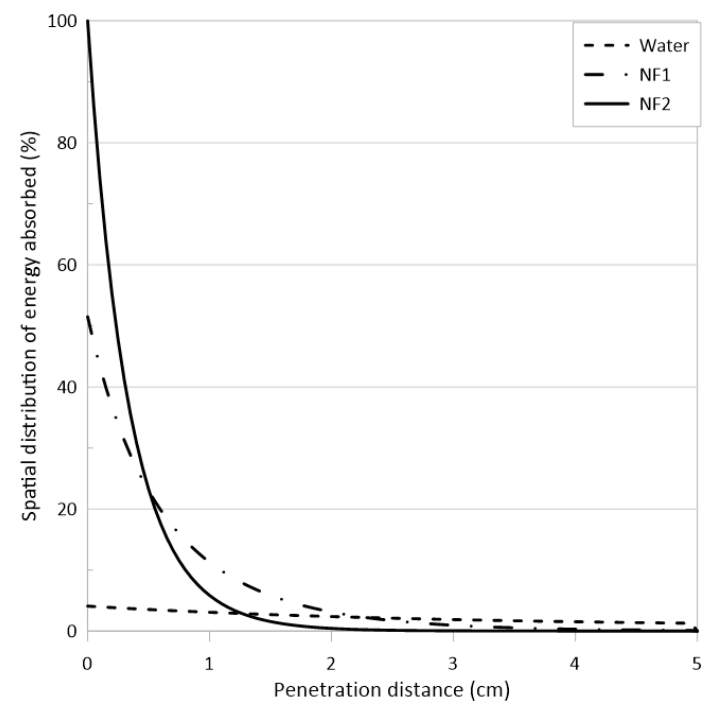

Figure 11 Spatial distribution of the absorbed energy according to the penetration distance of the base fluid (water) and the water-based carbon nanofluids at two different concentrations

(NF1 and NF2).

To directly compare the differences found, the data in Figure 11 were normalised to the highest distribution value (reached by NF2). The results obtained in Figure 11 clearly show that the energy is mainly absorbed in the first layers of nanofluids. Moreover, as expected, the higher the absorption coefficient is, the lower the penetration distance required for complete absorption will be. In any case, both NFs exhibit an absorption of up to $97 \%$ of the incident energy for a penetration distance of $2 \mathrm{~cm}$ from the cuvette surface. These results complement the conclusions extracted from Figure 10, where the nanofluids demonstrate complete solar energy absorption with a propagation of only a few centimetres. The results from Figure 10 prove that the absorbed energy is also stored in the same region, thus confirming that the use of nanofluids is an appealing approach to the development of compact solar collectors, allowing a reduction in the volume of liquid necessary for solar energy absorption and storage.

\subsection{Photothermal Conversion Efficiency}

The increment over ambient temperature $\left(21^{\circ} \mathrm{C}\right)$ of the base fluid and both solar NFs when exposed to the artificial sunlight simulator are presented in Figure 12. During the initial heating stage, the increase in temperature is approximately linear with irradiation time, and it deviates from this trend as the temperature increases due to the higher heat dissipation. A final constant temperature in the liquid is reached when the heat loss balances the absorbed light power. Due to the optical absorption of the NP, the temperatures of the NFs increase more quickly and reach higher final temperatures than that of the base fluid. After an irradiation time of 6000 seconds, water reaches a temperature increase of $9.3{ }^{\circ} \mathrm{C}$ while the NFs with $3 \mathrm{mg} \cdot l^{-1}$ and $33 \mathrm{mg} \cdot l^{-1}$ reach $20^{\circ} \mathrm{C}$ and $24.2^{\circ} \mathrm{C}$ respectively. 


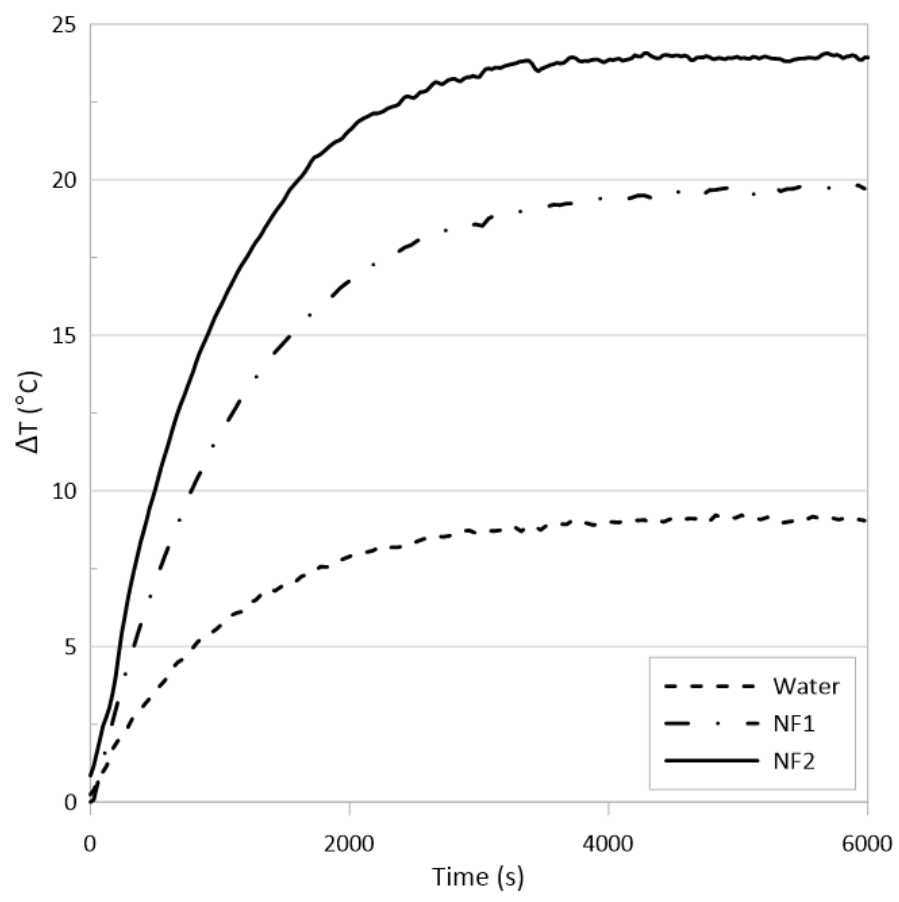

Figure 12 Temperature profiles of base fluid (water) and the water-based carbon nanofluids at two different concentrations (NF1 and NF2) with irradiation time.

Based on the temperature increments shown in Figure 12, the power absorbed by the samples and the photothermal efficiencies are obtained by means of Equations 8 to 12, once the stationary final temperatures are reached in the fluids. Table 1 shows the temperature increment reached by each fluid and the photothermal conversion efficiencies.

Table 1. Maximum temperature increment reached and photothermal conversion efficiencies for the three different samples: water and both water-based carbon nanofluids.

\begin{tabular}{c|ccc} 
& Water & NF1 & NF2 \\
\hline$\Delta T_{\max }\left({ }^{\circ} \mathrm{C}\right)$ & 9.3 & 20 & 24.2 \\
$\eta(\%)$ & 28.7 & 60.2 & 86.1
\end{tabular}

Comparing these results with previous works is not an easy task for the nanofluids, due to different nanoparticle types, concentrations, size distributions, etc. Also, different set-ups, equation have been used for evaluating water photothermal conversion efficiency in addition to shorter times: 60 seconds Zhang et at. [46] and 300 seconds in Jin et al. [55] and Zeiny et at. [43] instead of the 6000 seconds of the present work. Taking these into account, the values obtained for photothermal conversion efficiency for water in this work $(28.7 \%)$ is within the range of values obtained in previous studies: $9.4 \%$ [55], 20\% [43] and about $44 \%$ [46].

Remarkable increases in photothermal conversion efficiencies are observed for the water-based carbon NF even with very small NP concentrations. Compared to the base fluid (water), which obtained an efficiency of around $29 \%$, for NF this value increases to over $86 \%$ at an NP concentration of $33 \mathrm{mg}^{-1}{ }^{-1}$. In this variable it is also observed that the higher the NP 
concentration is, the higher the photothermal efficiency enhancement will be. Overall, waterbased carbon NF with low NP concentrations present interesting photothermal performances that can be applied in real applications based on volumetric solar collectors.

\section{Conclusions}

During the development of this work, a colloid composed of carbon nanoparticles in water synthesised by a two-step method has been shown to be a promising solar nanofluid that improves solar energy harvesting and conversion into thermal energy. The carbon nanoparticles form clusters of approximately $200 \mathrm{~nm}$ and exhibit good stability even at temperatures up to 85 ${ }^{\circ} \mathrm{C}$. Regarding the optical properties of the NFs evaluated, some important conclusions can be drawn:

- The spectral transmittance and the absorption coefficient of the water-based carbon NF with a higher NP concentration ( $33 \mathrm{mg} \cdot \mathrm{l}^{-1}$ ) improved (for the measured range of 400$1100 \mathrm{~nm}$ ) by about $87 \%$ and $3200 \%$ respectively with regard to those variables of the base fluid (water).

- The contribution of scattering to absorption is less than $10 \%$; hence, direct absorption predominates and explains the enhanced efficiency of the conversion of solar radiation to thermal energy.

- Sunlight energy absorption and storage evaluated by $F(x)$ and $S_{a b s}(x)$ indicate that the penetration depth of solar light can be interestingly reduced by using NF. For example, $100 \%$ radiation absorption is achieved after $2 \mathrm{~cm}$ of NF with maximum concentration, while in the case of water less than $20 \%$ of the total radiation is absorbed. This fact indicates that the use of NF in a solar collector would improve its compactness, thereby reducing the volume of liquid required and generally lowering the cost of the system.

- Remarkable enhancements of the photothermal conversion efficiencies were observed for the water-based carbon NF evaluated (up to $200 \%$ when compared to base fluids).

- A semiempirical methodology using Kubelka-Munk theory has been implemented to evaluate absorption coefficient, a key variable for solar nanofluids.

- A new formulation to estimate a global photothermal conversion efficiency based on energy balance and fitting the transient temperature evolution of the fluids has been developed.

Therefore, the low concentration water-based carbon NF exhibits good high-temperature stability and shows interesting optical properties to be utilised in practical low-temperature DASC systems.

\section{Acknowledgements}

The authors thank the financial support from the Generalitat Valenciana (Project: PROMETEU/2020/029). 


\section{References}

[1] International Energy Agency IEA, Solar Energy Perspectives, 2011, https://www.oecdilibrary.org/energy/solar-energy-perspectives_9789264124585-en

[2] P.M. Martinez, V.A. Pozdin, A. Papadimitratos, W. Holmes, F. Hassanipour, A.A. Zakkhidov, Dual use of carbon nanotube selective coatings in evacuated tube solar collector, Carbon 119 (2017) 133-141.

[3] R. Bertocchi, J. Karni, A. Kribus, Experimental evaluation of a non-isothermal high temperature solar particle receiver, Energy 29 (2004) 687-700.

[4] J.E. Minardi, H.N. Chuang, Performance of a "black" liquid flat-plate solar collector, Solar Energy 17 (1975) 179-183.

[5] T.P. Otanicar, P.E. Phelan, J.S. Golden, Optical properties of liquids for direct absorption solar thermal energy systems, Solar Energy 83 (2009) 969-977.

[6] E. Sani, N. Papi, L. Mercatelli, G. Zyla, Graphite/diamond ethylene glycol-nanofluids for solar energy applications, Renewable Energy 126 (2018) 692-698.

[7] A. Gimeno-Furio, L. Hernandez, N. Navarrete, R. Mondragon, Characterisation study of a thermal oil-based carbon black solar nanofluid, Renewable energy 140 (2019) 493-500.

[8] T.P. Otanicar, P.E. Phelan, R.S. Prasher, G. Rosengarten, R.A. Taylor, Nanofluid-based direct absorption solar collector, J. Ren. and Sust. Energy 2 (2010) 033102.

[9] A. Moradi, E. Sani, M. Simonetti, F. Francini, E. Chiavazzo, P. Asinari, Carbon-Nanohorn based nanofluids for a direct absorption solar collector for civil application, J. Nanosci Nanotechnol. 15 (2015) 3488-95.

[10] A. Lenert, E.N. Wang, Optimization of nanofluid volumetric receivers for solar Thermal energy conversion, Solar Energy 86 (2012) 253-265

[11] Z. Luo, C. Wang, W. Wei, G. Xiao, M. Ni, Performance improvement of a nanofluid solar collector based on direct absorption collection (DAC) concepts, Int. J of Heat and Mass Transf. 75 (2014) 262-271.

[12] E. Sani, S. Barison, C. Pagura, L. Mercatelli, P. Sansoni, D. Fontani, D. Jafrancesco, F. Francini, Carbon nanohorns-based nanofluids as direct sunlight absorbers, Optics Express 18 (2010) 51795187. 
[13] E. Sani, L. Mercatelli, S. Barison, C. Pagura, F. agrestic, L. Colla, P. Sansoni, Potential of carbon nanohorn- based suspensions for solar thermal collectors, Solar Energy Materials and Solar Cells 95 (2011) 2994-3000.

[14] R.A. Taylor, P.E. Phelan, T.P. Otanicar, R. Adrian, R. Prasher, Nanofluid optical property characterization: towards efficient direct absorption solar collectors, Nanoscale Research Letters 6 (2011) 1-11.

[15] N. Goel, R.A. Taylor, T. Otanicar, A review of nanofluid-based direct absorption solar collectors: Design considerations and experiments with hybrid PV/Thermal and direct steam generation collectors, Renewable Energy 145 (2020) 903-913.

[16] W. Chamsa, S. Brundavanam, C. Fung, D. Fawcett, G. Poinern, Nanofluid types, their synthesis, properties and incorporation in direct solar thermal collectors: a review, Nanomaterials 7 (2017) 131.

[17] S. Delfani, M. Karami, M.A. Akhavan-Behabadi, Performance characteristics of a residentialtype direct absorption solar collector using MWCNT nanofluid, Renewable Energy 87 (2016) 754764.

[18] S.M. Ldjevardi, A. Asnaghi, P.S. Izadkhast, A.H. Kashani, Applicability of graphite nanofluids in direct solar energy absorption, Solar Energy 94 (2013) 327-334.

[19] M. Karami, M.A. Akhavan-Behabadi, S. Delfani, A. Ghozatloo, A new application of carbon nanotubes nanofluid as working fluid of low-temperature direct absorption solar collector, Solar Energy Materials and Solar Cells 121 (2014) 114-118.

[20] M. Karami, M.A. Akhavan-Behabadi, S. Delfani, M. Raisee, Experimental investigation of CuO nanofluid-based Direct Absorption Solar Collector for residential applications, Ren. and Sust. Ener. Reviews 52 (2015) 793-801.

[21] T.B. Gorji, A.A. Ranjabar, S.N. Mirzababaei, Optical properties of carboxyl functionalized carbon nanotube aqueous nanofluids as direct solar thermal energy absorbers, Solar Energy 119 (2015) 332-342.

[22] L. Mercatelli, E. Sani, A. Giannini, P Di Ninni, F. Martelli, G. Zaccanti, Carbon nanohorn-based nanofluids: characterization of the spectral scattering albedo, Nanoscale Research Letters 7 (2012) 96. 
[23] E. Sadeghinezhad, M. Mehrali, R. Saidur, M. Mehrali, S. Tahan, A. Reza Akhiani, H.S.C. Metselaar, A comprehensive review on graphene nanofluids: recent research, development and applications, Energy Conv. and Manag. 111 (2016) 466-487.

[24] R. Kathiravan, R. Kumar, A. Gupta, R. Chandra, P.K. Jain, Pool boiling characteristics of multiwalled carbon nanotube (CNT) based nanofluids over a flat plate heater, Int J Heat Mass Transf 54 (2011) 1289-96.

[25] W. Jiang, G. Ding, H. Peng, Measurement and model on thermal conductivities of carbon nanotube nanorefrigerants. Int J Therm Sci 48 (2009) 1108-1115.

[26] T.P. Teng, C.M. Cheng, F.Y. Pai, Preparation and characterization of carbon nanofluid by a plasma arc nanoparticles synthesis system, Nanoscale Res Lett 6 (2011).

[27] M.N.A.W.M. Yazid, N.A.C. Sidik, R. Mamat, G. Najafi, A review of the impact of preparation on stability of carbon nanotube nanofluids, Int. Com. In Heat and Mass Transf. 78 (2016) 253263.

[28] T. J. Choi, S. P. Jang, M.A. Kedzierski, Effect of surfactants on the stability and solar thermal absorption characteristics of water-based nanofluids with multi-walled carbon nanotubes, Int. J. of Heat and Mass Transf. 122 (2018) 483-490.

[29] L. Mercatelli, E. Sani, G. Zacantti, F. Martelli, P. Di Nini, S. Barison, C. Pagura, F. Agresti, D. Jafrancesco, Absorption and scattering properties of carbon nanohorn-based nanofluids for direct sunlight absorbers, Nanoscale Res. Let. 6 (2011) 282

[30] C.F. Bohren, D.R. Huffman, Absorption and scattering of light by small particles, John Wiley \& Sons, 1983.

[31] O. Mahian, A. Kianifar, S.A. Kalogirou, I. Pop, S. Wongwises, A review of the applications of nanofluids in solar energy. Int. J of Heat and Mass Transf. 57(2) (2013) 582-594.

[32] N. Goel, R.A. Taylor, T. Otanicar, A review of nanofluid-based direct absorption solar collectors: Design considerations and experiments with hybrid PV/Thermal and direct steam generation collectors. Renewable Energy, 145 (2020) 903-913.

[33] N. Hordy, D. Rabilloud, J.L. Meuniera, S. Coulombe, High temperature and long-term stability of carbon nanotube nanofluids for direct absorption solar thermal collectors, Solar Energy 105 (2014) 82-90. 
[34] V. Khullar, H. Tyagi, T.P. Otanicar, Y. Hewakuruppu, P. Modi, R.A. Taylor, Harvesting solar thermal energy through nanofluid-based volumetric absorption systems, Int. J. of Heat and Mass Transf. 77 (2014) 377-384.

[35] M. Karami, MA. Bahabadi, S. Delfani, A. Ghozatloo, A new application of carbon nanotubes nanofluid as working fluid of low-temperature direct absorption solar collector, Sol Energy Mater Sol Cells 121 (2014) 114-8.

[36] I.M. Mahbubul, M.M.A. Khan, N.I. Ibrahim, H.M. Ali, F.A. Al-Sulaiman, R. Saidur, Carbon nanotube nanofluid in enhancing the efficiency of evacuated tube solar collector, Renew. Energy 121 (2018) 36-44.

[37] S. Iranmanesh, H.C. Ong, B.C. Ang, E. Sadeghinezhad, A. Esmaeilzadeh, M. Mehrali, Thermal performance enhancement of an evacuated tube solar collector using graphene nanoplatelets nanofluid, J. Clean. Prod. 162 (2017) 121-129.

[38] Y. Tong, J. Kim, H. Cho, Effects of thermal performance of enclosed-type evacuated U-tube solar collector with multi-walled carbon nanotube/water nanofluid, Renew. Energy 83 (2015) 463-473.

[39] S. Delfani, M. Karami, M.A. Akhavan-Behabadi, Performance characteristics of a residentialtype direct absorption solar collector using MWCNT nanofluid, Renew. Energy 87 (2016) 754764.

[40] M. Vakili, S.M. Hosseinalipour, S. Delfani, S. Khosrojerdi, M. Karami, Experimental investigation of graphene nanoplatelets nanofluid-based volumetric solar collector for domestic hot water systems, Sol. Energy 131 (2016) 119-130.

[41] D. Han, Z. Meng, D. Wu, C. Zhang, H. Zhu, Thermal properties of carbon black aqueous nanofluids for solar absorption, Nanoscale Res. Lett. 6 (2011) 457

[42] H. Wang, W. Yang, L. Cheng, C. Guan, H. Yan, Chinese ink: High performance nanofluids for solar energy, Sol. Energy Mater. Sol. Cells. 176 (2018) 374-380

[43] A. Zeiny, H. Jin, L. Bai, G. Lin, D. Wen, A comparative study of direct absorption nanofluids for solar thermal applications, Sol. Energy 161 (2018) 74-82

[44] E.T. Ulset, P. Kosinski, B.V. Balakin, Solar steam in an aqueous carbon black nanofluid, Appl. Therm. Eng. 137 (2018) 62-65 
[45] S.K. Hazra, S. Ghosh, T.K. Nandi, Photo-thermal conversion characteristics of carbon blackethylene glycol nanofluids for applications in direct absorption solar collectors, Applied Thermal Engineering 163 (2019) 114402

[46] Zhang, H., Chen, H.-J., Du, X., Wen, D., Photothermal conversion characteristics of gold nanoparticle dispersions. Sol. Energy 100 (2014) 141-147.

[47] A. Gimeno-Furio, N. Navarrete, R. Mondragon, L. Hernandez, R. Martinez-Cuenca, L. Cabedo, J.E. Julia, Int. J. of Heat and Mass Transf. 113 (2017) 908-913.

[48] A. Gimeno-Furio, N. Navarrete, R. Martinez-Cuenca, J.E. Julia, L. Hernandez, Influence of high temeprature exposure on the thermal and optical properties of thermal oil-based solar nanofluids, J of Nanof. 7 (2018) 1045-1052.

[49] Zetasizer Nano User Manual, Malvern Instruments, Ltd, 2013.

[50] A. Jaradat, MA. Al-Akhras, G. Makhadmeh, K. Aljarrah, A. Al-Omari, Z. Ababneh, MM. Masadeh, HM. Al-Khateeb, BA. Albiss, M. Alshorman, Artificial semi-rigid tissue sensitized with natural pigments: Effect of photon radiations, J. Pharm. Bioallied Sci. 3 (2011) 266-276.

[51] ASTM International, Standard Tables for Reference Solar Spectral Irradiances: Direct Normal and Hemispherical on $37^{\circ}$ Tilted Surface, G173 (2012).

[52] T. Schneider, D. Leduc, J. Cardin, C. Lupi, H. Gundel, Optical characterisation of a three layer waveguide structure by m-Lines spectroscopy, Ferroelectrics 352 (2007) 50-60.

[53] J. Qu, M. Tian, X. Han, R. Zhang, Q. Wang, Photo-thermal conversion characteristics of MWCNT- $\mathrm{H}_{2} \mathrm{O}$ nanofluids for direct solar thermal energy absorption applications, Appl. Ther. Eng. 124 (2017) 486-493.

[54] T.R. Wagner, W.G. Houf, F.P. Incropera, Radiative property measurements for india ink suspensions of varying concentration, Solar Energy 25 (1980) 549-554.

[55] H. Jin, G. Lin, L. Bai, A. Zeiny, D. Wen, Steam generation in a nanoparticle-based solar receiver, Nano Energy 28 (2016) 397-406. 